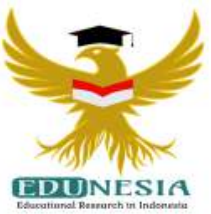

\title{
Interaksi Kekuatan Otot Tungkai Terhadap Keterampilan Passing Atas Pada Permainan Bola Voli
}

\author{
Tirto Parta Wibowo'; Edho Pranata2; ${ }^{1}$ Antomie $^{3}$ \\ 1,2,3Pendidikan Jasmani, Universitas Dehasen Bengkulu, Indonesia \\ ${ }^{1}$ Corresponding Email: tito_wibowo99@yahoo.com, Phone Number : 0812 xxxx xxxx
}

\section{Article History:}

Received: Juli 13, 2020

Revised: Agust 15, 2020

Accepted: Sept 01, 2020

Published: Nov 01, 2020

Keywords:

Passing Skills, Strength.

Kata Kunci:

Kekuatan,

Keterampilan passing.

How to cite:

Wibowo, T.P., Pranata, E., \& Antomie. (2020). Interaksi Kekuatan Otot Tungkai Terhadap Keterampilan Passing Atas Pada Permainan Bola Voli. Edunesia : Jurnal Ilmiah Pendidikan, 1 (3): 41-45

This is an open access article under the CC-BY-NC-ND license (c) $(1) \circledast$
Abstract: Based on the observations of researchers on the implementation of Activities in SMA Negeri 1 Ulu Musi, District of Four Lawang, that the passing ability of students is not good so that it often causes the ball to not be exact when doing it. This problem is thought to be caused by several factors, including low levels of leg muscle strength. This study aims to determine the interaction of leg muscle strength on upper passing skills in volleyball games. This research method is a correlational method. The population of this research was all students of Class X of SMA 1Ulu Musi as many as 20 people while the samples were taken in total sampling. The place of the research was at SMA Negeri 1 Ulu musi, while the time of the study was February-March 2020. Data on leg muscle strength were taken with vertical tests jump, and passing ability data is taken by passing the top test. The data analysis technique of this research uses correlation analysis techniques. The results of the data analysis show that: There is a significant relationship between leg muscle strength $(X)$ and upper passing skills $(Y)$ in high school students 1 Ulu Musi, with rxy $=0.90>\mathrm{r}(0.05)(20)=0.444$.

Abstrak: Berdasarkan pengamatan peneliti terhadap pelaksanaan Kegiatan di SMA Negeri 1 Ulu Musi Kabupaten Empat Lawang, bahwa kemampuan passing para siswa kurang baik sehingga menyebabkan bola sering tidak tepat pasa saat melakukakannya. Masalah inilah diduga disebabkan oleh beberapa faktor, antara lain rendahnya tingkat kekuatan otot tungkai. Penelitian ini bertujuan untuk mengetahui Interaksi Kekuatan Otot Tungkai Terhadap Keterampilan Passing Atas pada permainan bola voli. Metode penelitian ini adalah metode korelasional. Populasi penelitian ini seluruh siswa Kelas X SMA Negeri 1 Ulu Musi sebanyak 20 orang sedangkan sampel diambil secara total sampling, Tempat pelaksanaan penelitian di Di SMA Negeri I Ulu musi, adapun waktu penelitian adalah bulan Febuari-Maret 2020. Data kekuatan otot tungkai diambil dengan tes vertical jump, dan data Kemampuan passing diambil dengan tes passing atas. Teknik analisis data penelitian ini menggunakan teknik dengan analisis korelasi. Hasil analisis data menunjukkan bahwa: Terdapat hubungan yang signifikan antara kekuatan otot tungkai $(\mathrm{X})$ terhadap keterampilan passing atas $(\mathrm{Y})$ pada siswa SMA Negeri 1 Ulu Musi, dengan rxy $=0,90>\mathrm{r}(0,05)(20)$ $=0,444$ 


\section{A. Pendahuluan}

Pendidikan jasmani dan olahraga pada dasarnya adalah merupakan proses dalam perencanaan, pengarahan sumber daya pendidikan melalui aktifitas jasmani dan olahraga yang terpilih untuk mencapai tujuan pendidikan secara efektif dan efesien (Supriyadi, 2019). Pada hakikatnya pendidikan jasmani dan olahraga merupakan proses pendidikan yang memanfaatkan aktifitas fisik (jasmani) dan olahraga untuk menghasilkan perubahan dalam individu, baik dalam hal fisik, mental dan emosional (Nugroho, 2019; Wati, 2019).

Dalam perkembanganya olahraga pada saat ini sudah berkembang dengan cepat, hal ini dapat dilihat dari masyarakat yang sudah semakin menyadari akan pentingnya aktivitas berolahraga (Prasetyo, 2013; Okilanda, 2018). Adapun keolahragaan terkhusus yang mengarah ke prestasi menjadi suatu alasan seseorang dalam berolahraga (Utami, 2015). Sejalan dengan perkembangan dan peningkatan fisik yang beranjak matang maka perkembangan motorik sudah dapat terkoordinasi dengan baik dari tingkat anak-anak, remaja bahkan ke tingkat dewasa (Aghnaita, 2017; Sudirjo \& Alif, 2018).

Tujuan pendidikan jasmani dan olahraga sudah tercakup dalam pemaparan di atas, yaitu memberikan kesempatan kepada anak untuk mempelajari berbagai kegiatan guna membina sekaligus mengembangkan potensi anak yang meliputi aspek penilaian yaitu, afektif, kognitif dan psikomotor. Hal tersebut seiring dengan isi Undang-Undang Republik Indonesia Nomor 3 tahun 2005 Pasal 1 ayat 3 tentang Sistem Keolahragaan Nasional yang menyatakan bahwa "Olahraga adalah segala kegiatan yang sistematis untuk mendorong, membina, serta mengembangkan potensi jasmani, rohani, dan sosial ".

Tujuan tersebut harus bisa dicapai melaui kegiatan pembelajaran yang direncanakan secara matang dengan berpedoman pada ilmu mendidik. Olahraga merupakan media untuk mendorong pertumbuhan fisik, keterampilan motorik, pengetahuan dan penalaran (Fadilah, 2016). Olahraga juga merupakan merupakan kebutuhan bagi setiap orang, karena semua orang pasti ingin sehat, tidak seorangpun yang ingin sakit atau terganggu kesehatan motorik, pengetahuan dan penalaran. Olahraga juga merupakan merupakan kebutuhan bagi setiap orang, karena semua orang pasti ingin sehat, tidak seorangpun yang ingin sakit atau terganggu kesehatannya.

Olahraga juga mempunyai peranan yang sangat penting untuk membantu tercapainya kebugaran jasmani (Rubiatno, 2016). Pembekalan pengalaman belajar pendidikan jasmani diarahkan untuk membina pertumbuhan faktor fisik dan pengembangan mental yang lebih baik, sekaligus membentuk pola hidup yang sehat.

Dari beberapa penjelasan di atas yang berhubungan dengan olahraga bolavoli yang ada di SMA Negeri 1 Ulu Musi Kabupaten Empat Lawang, perlu adanya peningkatan kembali mengenai keterampilan passing atas, hal ini berkaitan dengan faktor pemahaman bermain bolavoli yang kurang baik serta kekuatan otot yang masih kurang kuat. Hal ini dikarenakan pada saat observasi pembelajaran yang dijalani siswa banyak yang melakukan passing atas masih terlalu lemah dan salah dalam melakukan gerakannya. Passing atas ini dibutuhkan ketepatan dalam memberikan umpan yang akurat, kuat karena bukan saja otot yang digunakan, namun keterampilan dasar harus dimiliki oleh setiap siswa.

Berdasarkan penjelasan mengenai teknik dasar yang ada di atas, teknik passing atas merupakan salah satu teknik yang harus dikuasi oleh setiap siswa. Passing atas merupakan salah satu teknik yang selalu digunakan pemain 4 mengembangkan pola permainan. Setiap pemain dalam melakukan passing atas harus selalu ditingkatkan guna untuk menghasilkan pola permainan yang baik. 


\section{B. Metode}

Metode penelitian ini mengunakan dua variabel dimana variabel bebas disini adalah kekuatan otot tungkai sebagai variabel $(X)$, sedangkan variabel terikatnya adalah keterampilan passing atas sebagai $(\mathrm{Y})$. Metode penelitian yang digunakan dalam penelitian ini adalah dengan menggunakan metode korelasional (correlational research). Menurut Subagyo (2015)“Metode penelitian merupakan suatu cara atau jalan untuk memperoleh kembali pemecahan terhadap segala permasalahan". Oyek penelitian sebagai sasaran untuk mendapatkan dan mengumpulkan data disebut populasi (Subagyo, 2015). Populasi dalam penelitian ini adalah siswa kelas sepuluh (X) di SMA Negeri 1 Ulu Musi Kabupaten Empat Lawang berjumlah 20 orang.

Menurut Subagyo (2015) "sampel diambil dalam penelitian sebagai pertimbangan efesiensi dan mengarah pada sentralisasi permasalahan dengan memfokuskan pada sebagian dari populasinya". Sampel yang digunakan dalam penelitian ini adalah dengan menggunakan total sampling. Dimana teknik sampel ini diambil secara keseluruhan dari populasi yang ada. Adapun sampelnya penelitian ini berjumlah berjumlah 20 orang siswa.

Teknik analisis dalam penelitian ini adalah analisis kuantitatif yang digunakan untuk membahas masalah yang dinamis dengan menggunakan data yang berupa angkaangka. Data yang diperoleh akan dianalisis secara statistik dengan uji korelasi berguna untuk memilih variabel bebas yang memang didukung oleh data. Untuk mengetahui interaksi kekuatan otot tungkai terhadap keterampilan passing atas pada permainan bolavoli di SMA Negeri 1 Ulu Musi Kabupaten Empat Lawang.

\section{Hasil dan Pembahasan}

Passing atas merupakan salah satu teknik dasar dari permainan bolavoli yang sangat penting dimiliki oleh seorang pemain. Passing atas Teknik atau cara bermain bolavoli yang benar harus mengikuti arahan dari seorang pelatih atau guru, hal ini akan berdampak baik bagi pemain atau siswa. Adapun salah satu teknik yang harus dikuasai seorang pemain atau siswa adalah passing. Passing terdiri dari passing atas dan passing bawah. Passing adalah mengoperkan bola kepada teman sendiri dalam satu regu dengan suatu teknik tertentu, sebagai langkah awal untuk menyusun pola serangan ke pihak lawan.

Berdasarkan hasil penelitian menunjukan bahwa ada hubungan yang signifikan antara Kekuatan Otot Tungkai terhadap keterampilan passing atas pada SMA Negeri 1 Ulu Musi Kabupaten Empat Lawang, dengan nilai rx.y $=0,90>r(0,05)(20)=0,444$. Dari hasil penelitian ini passing atas merupakan salah satu teknik yang sangat penting dalam permainan bolavoli. Teknik dasar passing atas ini merupakan cara untuk menciptakan mengoper bola kepada teman satu tim untuk melakukan Smash/Spike sehingga mendapatkan poin. Ini disebabkan seluruh pemain memiliki kesempatan untuk menciptakan poin dan memenangkan pertandingan atau permainan. Pass-atas terbagi atas pada bola rendah Kunci pelaksanaannya: segera merandah dengan menekuk lutut menyentuh lantai agar dapat menempatkan badan di bawah bola., Pass-atas dengan bola di samping badan (Sideway Overhand Pass), Pass-atas dengan bergeser mundur (Backward Overhand Pass), Pass-atas dengan bergerak mundur diagonal 45 derajat (45 Degree Diagonal Overhand Pass), Pass-atas dengan meloncat (Overhand Jumping Pass), Pass-atas ke belakang (Overhand )dan Pass-atas ke belakang dengan berputar 180 derajat (Reverse Overhand Back Pass).Karena passing atas adalah operan kepada teman satu tim 
agar mendapatkan poin dan menentukan kemenangan, kekuatan otot tungkai dalam bola voli dapat disebutkan sebagai poin yang penting dalam melakukan passing atas yang cepat dalam setiap aktivitas passing atas. Kekuatan Otot Tungkai adalah komponen yang sangat penting untuk meningkatkan kondisi fisik secara keseluruhan. Kekuatan otot merupakan salah satu unsur kondisi fisik yang memiliki peranan penting dalam kegiatan olahraga khusunya olahraga bola volil, baik sebagai unsur pendukung dalam suatu gerak tertentu maupun unsur utama dalam upaya pencapaian teknik gerak yang sempurna. Otot yang kuat ternyata berpengaruh terhadap kecepatan gerak. Otot yang lebih kuat bergerak atau bereaksi lebih cepat dari pada otot yang lemah. Passing atas yang tepat dan cepat membutuhkan latihan Kekuatan Otot Tungkai yang terprogram dan dengan bimbingan pelatih untuk mengarahkan bagiamana dapat menghasilkan passing atas yang terarah dengan teknik yang benar dan tepat.

Dari penjelasan di atas dapat disimpulkan bahwa salah satu tahapan yang harus dilakukan didalam melakukan passing atas harus memiliki Kekuatan Otot Tungkai yang bagus. Pernyataan inilah yang menjadikan dasar bahwa Kekuatan Otot Tungkai sangat dibutuhkan dalam melakukan passing atas dalam permainan bola voli. Dengan Kekuatan Otot Tungkaiyang besar maka persentase keberhasilan dalam melakukan passing atas akan semakin tinggi

\section{Kesimpulan}

Berdasarkan hasil penelitian dan pembahasan, maka didapat kesimpulan sebagai berikut : Terdapat hubungan yang signifikan antara Kekuatan Otot Tungkai $(X)$ terhadap keterampilan passing atas. pada siswa di SMA Negeri 1 Ulu Musi Kabupaten Empat Lawang, dengan nilai $r x y=0,90>r(0,05)(20)=0,444$.

Berdasarkan simpulan di atas ada beberapa saran yang dapat disampaikan yaitu:

1. Bagi pelatih/Guru bolavoli agar dapat memberikan materi yang tepat untuk melatih keterampilan passing atas sehingga dapat mendukung peningkatan kualitas hasil latihan.

2. Bagi siswa agar dapat mengembangkan keterampilan passing atas dalam permainan bolavoli dengan menggunakan Kekuatan Otot Tungkai.

3. Bagi peneliti yang ingin melanjutkan penelitian ini agar dapat menemukan variabel lain yang dapat memberikan sumbangsih terhadap keterampilan passing atas dalam permainan bola voli selain Kekuatan Otot Tungkai.

\section{Daftar Pustaka}

Aghnaita, A. (2017). Perkembangan Fisik-Motorik Anak 4-5 Tahun Pada Permendikbud no. 137 Tahun 2014 (Kajian Konsep Perkembangan Anak). Al-Athfal: Jurnal Pendidikan Anak, 3(2), 219-234.

Fadlilah, A. R. A. (2016). Studi komparatif tingkat kebugaran jasmani peserta didik laki-laki kelas 4, 5 dan 6 di SDN Mojolangu 04 Kecamatan Lowokwaru Kota Malang/Agung Reza Arief Falillah (Doctoral dissertation, Universitas Negeri Malang).

Nugroho, W. A. (2019). Survei Problematika Pelaksanaan Kurikulum 2013 Dalam Pembelajaran Pendidikan Jasmani Olahraga Dan Kesehatan Pada Siswa Kelas VIII SMP N 2 Ambarawa Tahun Pelajaran 2016/2017 (Doctoral dissertation, UNNES). 
Okilanda, A. (2018). Revitalisasi Masyarakat Urban/Perkotaan Melalui Olahraga Petanque. Halaman Olahraga Nusantara (Jurnal Ilmu Keolahragaan), 1(1).

Prasetyo, Y. (2013). Kesadaran masyarakat berolahraga untuk peningkatan kesehatan dan pembangunan nasional. Medikora, 11(2).

Rubiyatno, R. (2016). Peranan Aktivitas Olahraga Bagi Tumbuh Kembang Anak. Jurnal Pendidikan Olahraga, 3(1), 54-64.

Sudirjo, E., \& Alif, M. N. (2018). Pertumbuhan dan Perkembangan Motorik: Konsep Perkembangan dan Pertumbuhan Fisik dan Gerak Manusia. UPI Sumedang Press.

Supriyadi, D. (2019). Implementasi Manajemen Pembelajaran Pendidikan Jasmani untuk Menciptakan Pembelajaran yang Menyenangkan bagi Siswa. Jurnal Speed (Sport, Physical Education, Empowerment), 2(2), 20-26.

Utami, D. (2015). Peran Fisiologi Dalam Meningkatkan Prestasi Olahraga Indonesia Menuju Sea Games. Jorpres (Jurnal Olahraga Prestasi), 11(2).

Wati, W. W. (2016). Manajemen Pendidikan Dalam Upaya Meningkatkan Efektivitas Pembelajaran Pendidikan Jasmani Olahraga Dan Kesehatan Di Sdn Cibanteng Kabupaten Bandung (Doctoral dissertation, UNPAS). 